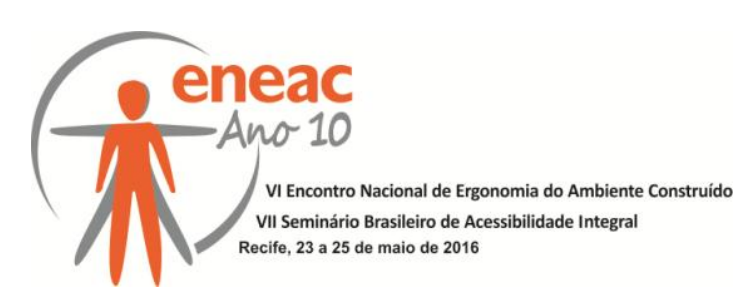

\title{
ANÁLISE DA ACESSIBILIDADE DA ESCOLA ESTADUAL RIO BRANCO NA CIDADE DE PATOS-PB
}

\author{
OLIVEIRA, Ane Francisca (1); \\ BATISTA, Andreza (2); \\ RODRIGUES, Joyce(3); \\ FERNANDES, Júlio César (4)
}

(1) Faculdades Integradas de Patos, graduanda em Arquitetura e Urbanismo

e-mail: anny lima oliveira16@hotmail.com

(2) Faculdades Integradas de Patos, graduanda em Arquitetura e Urbanismo

e-mail: andrezambatista@gmail.com

(3) Faculdades Integradas de Patos, graduanda em Arquitetura e Urbanismo

e-mail: joycedantas23@outlook.com

(4) Faculdades de Tecnologia da Paraíba, Mestre em Engenharia de Produção (UFRN)

e-mail:julio dsi@yahoo.com.br

\begin{abstract}
RESUMO
Este artigo apresenta a avaliação da acessibilidade na Escola Estadual de Ensino Fundamental Rio Branco, buscando revelar o que se encontra inadequado para a circulação e bem estar de pessoas com deficiência e mobilidade reduzida, a partir da recente norma de acessibilidade NBR 9050 (ABNT, 2015). Apresentando também o que poderia ser feito para que o local se tornasse mais seguro e viável para todos que o utilizam: alunos, funcionários e possíveis frequentadores. A partir de medições e registros fotográficos, foram detectadas várias falhas na acessibilidade da instituição.
\end{abstract}

Palavras chave: Acessibilidade, NBR 9050, escola, pessoa com deficiência.

\begin{abstract}
This article presents the accessibility evaluation at the State Elementary Rio Branco Education School, seeking to expose the inadequacies for circulation and well-being of persons with disabilities and reduced mobility, from the brazilian standard of accessibility parameters NBR 9050 (ABNT, 2015). Moreover, the article suggests possible changes so that the space becomes safer and viable for all who use it: students, staff and potential goers. From the physical survey and photographic records compared to the norm, many problems were detected in the accessibility of the institution.
\end{abstract}

.Keywords: Accessibility, NBR 9050, school, disabled person.

\section{INTRODUÇÃO}

O censo de 2010 do IBGE aponta que cerca de $23,9 \%$ da população brasileira tem deficiência. Isso significa que mais de 45,6 milhões de pessoas com deficiência vivem no Brasil (IBGE, 2010). 


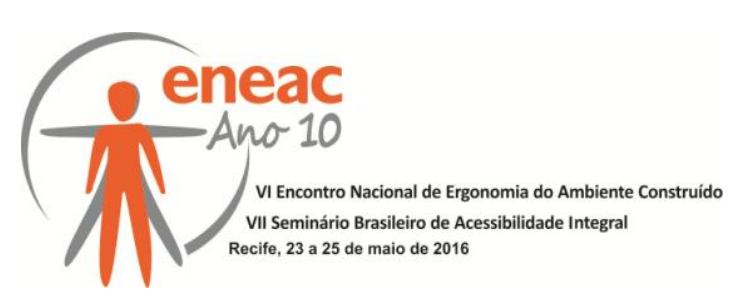

De acordo com a Nova lei de inclusão, "acessibilidade é direito que garante à pessoa com deficiência ou com mobilidade reduzida viver de forma independente e exercer seus direitos de cidadania e de participação social" (BRASIL, 2015).

Todas as pessoas, independente se possui ou não algum tipo de redução de mobilidade, necessitam de acessibilidade para ter sua qualidade de vida assegurada e conseguir realizar normalmente atividades do cotidiano.

O Decreto Federal 5.296 regulamenta que "estabelecimentos de ensino de qualquer nível, etapa ou modalidades, públicos e privados, proporcionarão condições de acesso e utilização de todos os seus ambientes ou compartimentos, para pessoas com deficiência ou mobilidade reduzida" (BRASIL, 2004).

Este artigo tem por objetivo analisar a acessibilidade da Escola Estadual de Ensino Fundamental Rio Branco, localizada no centro comercial da cidade de Patos-PB, apontando possíveis falhas e sugestões de melhorias. A Escola oferece vagas do $5^{\circ}$ ao $9^{\circ}$ ano do ensino fundamental, atendendo alunos de 9 a 16 anos, atualmente possui mais de 600 alunos matriculados, divididos nos turnos matutino e vespertino.

\section{ERGONOMIA E ACESSIBILIDADE}

Conceitua-se a Ergonomia como tecnologia projetual das comunicações entre homens e máquinas, trabalho e ambiente (MORAES \& SOARES, 1989 apud MORAIS \& MONT'ALVÃO, 2010). A ergonomia busca adaptar as ferramentas de trabalho ao homem, objetivando melhorar a saúde, segurança, satisfação e eficiência, proporcionando uma melhor qualidade de vida para seus usuários.

No Decreto Presidencial 5.296 a acessibilidade é descrita como condição para utilização, com segurança e autonomia, total ou assistida, dos espaços, mobiliários e equipamentos urbanos, das edificações, dos serviços de transporte e dos dispositivos, sistemas e meios de comunicação e informação, por pessoa com deficiência ou com mobilidade reduzida (BRASIL, 2004).

Produtos, instrumentos, equipamentos, tecnologias assistivas para pessoas com deficiência ou com mobilidade reduzida, devem favorecer a autonomia pessoal, total ou assistida (BRASIL, 2004). O mobiliário escolar deve ser um fator tão importante quanto à acessibilidade do local, esses dois fatores devem ser vistos como um conjunto que proporcionará um ambiente acessível e confortável para que todos possam usufruir do mesmo.

A Lei 13.146 garante aos deficientes o direito a educação, em todos os níveis e aprendizado ao longo da vida, para isso, os sistemas educacionais devem garantir condições de acesso, permanência, participação e aprendizagem, por meio da oferta de serviços e de recursos de acessibilidade que eliminem as barreiras e promovam a inclusão plena (BRASIL, 2015).

A quase absoluta totalidade dos edifícios escolares foi construída sem considerar acessibilidade e sem considerar que estes iriam ser utilizados por pessoas com deficiência, esta inadequação pode afetar a inclusão dos estudantes, gerando uma possível exclusão no sistema escolar (DISCHINGER \& MACHADO, 2006).

\section{METODOLOGIA}

A pesquisa de abordagem qualitativa teve como objetivo expor os problemas de acessibilidade na Escola Estadual Rio Branco. 


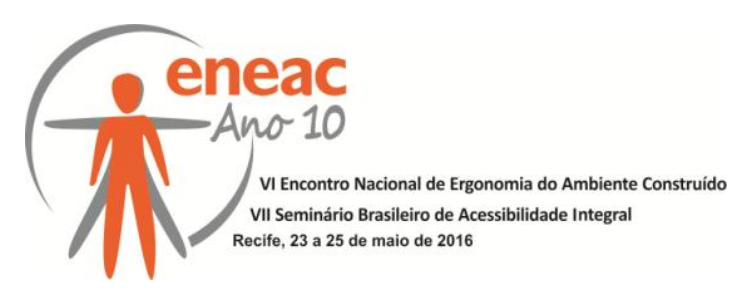

Para isso, foram realizadas pesquisas bibliográficas em livros, normas, artigos científicos e legislações que abordam temas envolvendo pessoas com deficiência, ambientes públicos, escolas, ergonomia e acessibilidade.

O levantamento físico do local foi realizado com o auxílio de uma fita métrica de $32 \mathrm{~m}$, além disso, foram utilizados métodos observacionais por meio de registros fotográficos. Após esta fase, foi realizada a análise dos dados, comparando-os com os parâmetros encontrados na NBR 9050 (ABNT, 2015).

O estudo se deteve à análise de dois trajetos: da calçada, a partir das rampas R1, R2 e R3, que leva a porta de entrada P1 da escola, passando pelas áreas de manobra A1 e A2 e pelas rampas $\mathrm{R} 4$ e $\mathrm{R} 5$, pela segunda porta de entrada $\mathrm{P} 2$, chegando à terceira porta $\mathrm{P} 3$, local onde as rotas são divididas, uma delas levando a área A4, aos corredores C1, C3 e C4 e a rampa $\mathrm{R} 6$ em direção à porta da biblioteca $\mathrm{P} 4$, o trajeto passa pelo corredor $\mathrm{C} 2$ que atravessa o ginásio, passa pela porta P6, pela circulação $\mathrm{C} 5$, levando a porta do banheiro $\mathrm{P} 7$, destinado às pessoas com deficiência conforme mostra a figura 1 a seguir.

Figura 1 - Rotas analisadas na Escola Rio Branco.

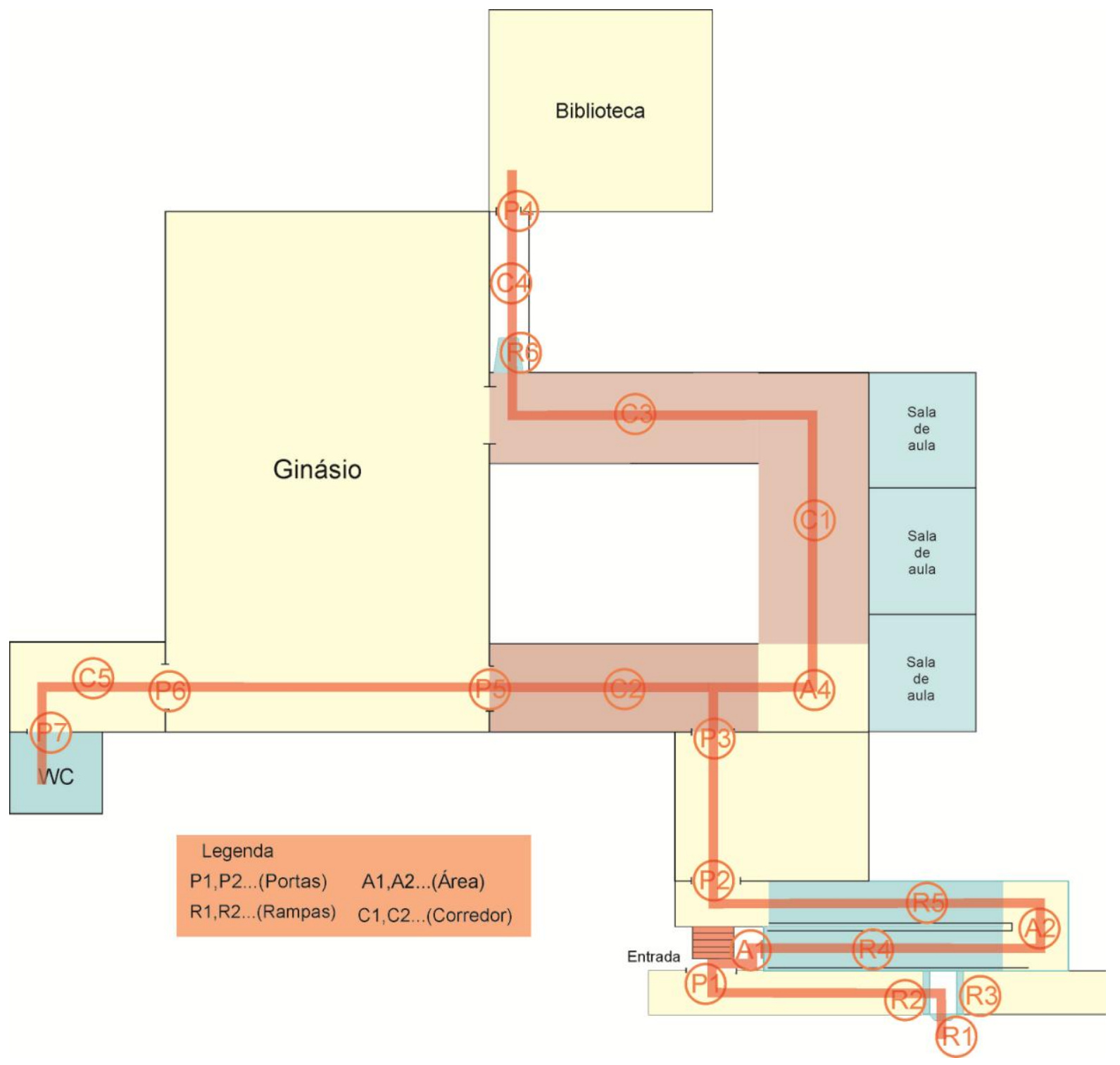

Fonte: Acervo pessoal. 


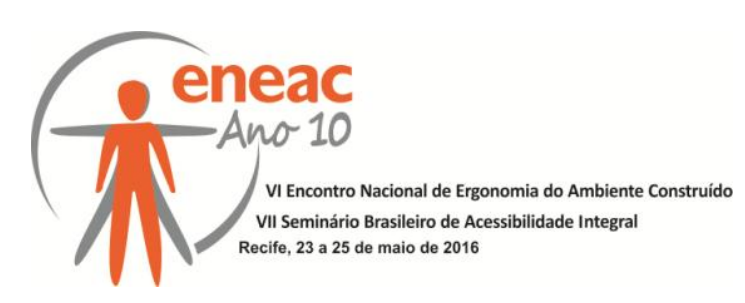

\section{ANÁLISE DA ACESSIBILIDADE}

Neste capítulo serão analisados todos os percursos estudados de acordo com a recente norma de acessibilidade NBR 9050 (ABNT, 2015).

Na figura 2 há um rebaixamento inadequado da calçada, pois o mesmo deveria deixá-la no nível da rua. A rampa $R 1$, que dá acesso à calçada possui altura de $0,05 \mathrm{~m}$, largura de $1,30 \mathrm{~m}$ e comprimento de $0,30 \mathrm{~m}$, resultando uma inclinação de $16,6 \%$, quando a inclinação para rampas com altura de até $0,80 \mathrm{~m}$ deve ser $8,33 \%$, de acordo com a NBR 9050 (ABNT, 2015). Assim, a rampa deveria ter $0,60 \mathrm{~m}$ de comprimento para atender à norma, sua largura de $1,30 \mathrm{~m}$ condiz com a NBR citada. Outro erro dessa rampa é a distância de $6 \mathrm{~cm}$ da mesma à calçada, quando deveria ser no máximo $1,5 \mathrm{~cm}$, conforme a NBR 9050 (ABNT, 2015)

As rampas $\mathrm{R} 2$ e $\mathrm{R} 3$ também estão inadequadas quanto às suas inclinações que é de $10,1 \%$, quando deveriam ser $8,33 \%$. Elas têm $0,08 \mathrm{~m}$ de altura e $0,79 \mathrm{~m}$ de comprimento, mas para ter a inclinação correta precisariam de $0,96 \mathrm{~m}$ de comprimento.

A faixa livre da calçada mede $1,87 \mathrm{~m}$, suprindo o que a NBR 9050 (ABNT, 2015) regulamenta que é um passeio de $1,20 \mathrm{~m}$.

Figura 2 - Rampa de acesso à calçada da escola - Acervo pessoal.

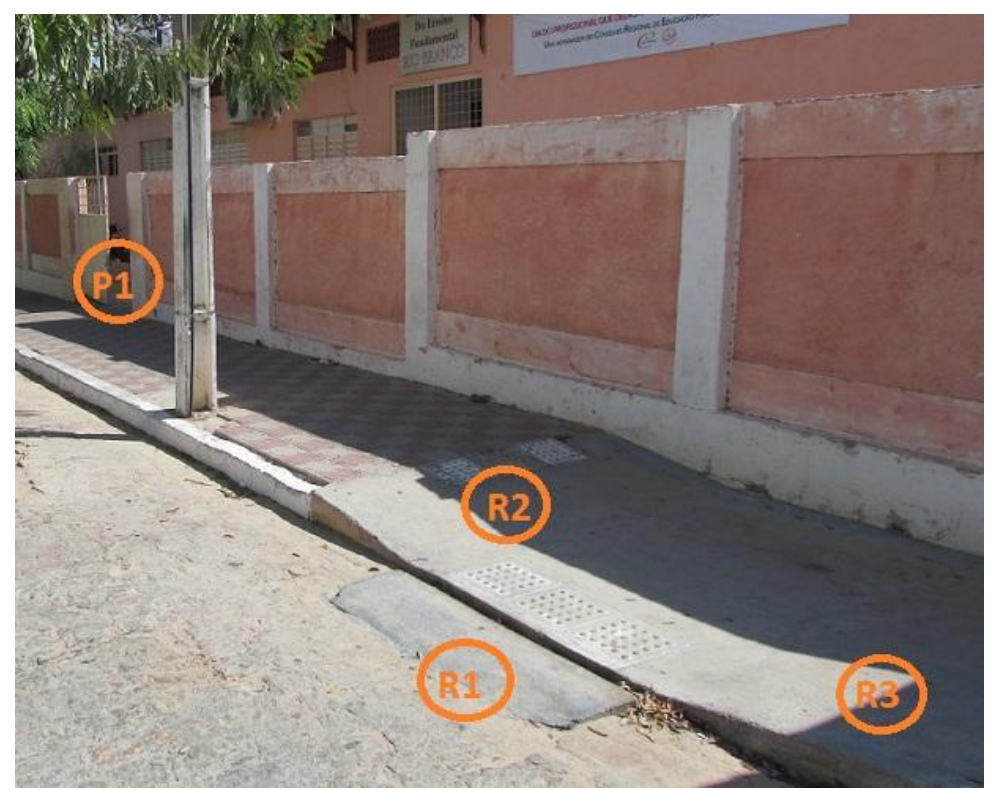

Fonte: Acervo pessoal.

Na figura 3 a porta P1 abre dos dois lados totalizando um vão de 2,70m, que atende à NBR 9050 (ABNT, 2015), porém possui fechadura interna inacessível para pessoas no exterior do edifício com altura de 1,13m, quando a norma limita essa altura entre 0,90m e 1,10m.

$\mathrm{A}$ área para manobra de $90^{\circ} \mathrm{A} 1$ tem dimensões de $0,90 \mathrm{~m} \times 1,20 \mathrm{~m}$, não atendendo ao que a NBR 9050 (ABNT, 2015) cobra, que é uma área de 1,20m×1,20m.

No início da rampa $\mathrm{R} 4$ há um desnível de $0,04 \mathrm{~m}$, que dificulta o acesso. A rampa tem $1,30 \mathrm{~m}$ de largura, $8,80 \mathrm{~m}$ de projeção horizontal e $0,30 \mathrm{~m}$ de altura, resultando em uma inclinação 


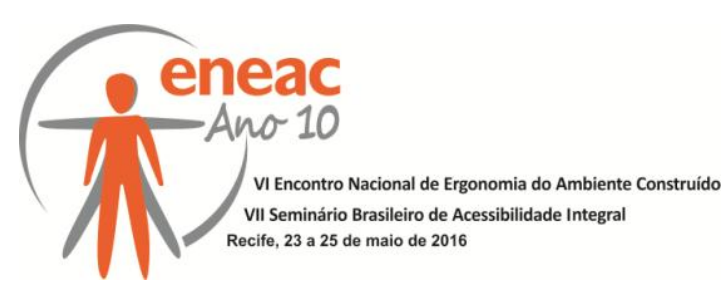

de 3,4\%, menor do que a NBR 9050 (ABNT, 2015) orienta, que é uma inclinação entre $6,25 \%$ e $8,33 \%$, portanto está adequada.

A área para manobra de $180^{\circ} \mathrm{A} 2$ tem dimensões de $2,60 \mathrm{~m} \times 2,05 \mathrm{~m}$, atendendo à norma, que regulamenta $1,50 \mathrm{~m}$ por $1,20 \mathrm{~m}$.

A rampa R5 tem dimensões de 1,30m de largura, 6,60m de projeção horizontal e $0,20 \mathrm{~m}$ de altura, resultando em uma inclinação de $3,0 \%$, estando adequada de forma análoga à rampa R4.

Tanto a rampa R4 como a R5 possuem corrimão apenas em um dos lados, quando deveriam possuir dos dois lados. Os corrimãos não possuem sinalização tátil, nem extremidades curvas como a NBR 9050 (ABNT, 2015) estabelece. Os corrimãos mais baixos possuem altura de $0,75 \mathrm{~m}$, mas de acordo com a norma eles deviam ter altura de 0,70m. Os corrimãos mais altos estão com a altura correta de $92 \mathrm{~cm}$, como a norma orienta.

Já a área para manobra de $90^{\circ} \mathrm{A} 3$ está incorreta, pois uma de suas dimensões para a manobra é de $0,95 \mathrm{~m}$, que é a largura da porta P2 por $1,30 \mathrm{~m}$ que é a largura do patamar da rampa $\mathrm{R} 5$.

A porta P2 tem um desnível de 0,04m que dificulta o acesso ao interior da escola. Foi observado in loco, que a largura dela é pequena para o fluxo de pessoas que a utilizam. A altura da porta P2 é de 2,25m, estando adequada, já que a NBR considera adequada a porta com altura mínima de 2,10m. Sua fechadura está incorreta, pois a NBR 9050 (ABNT, 2015) pede o uso de maçanetas de alavanca, para facilitar o acesso a pessoas com deficiência. A altura da fechadura também está inadequada, pois ela está a 1,13m do piso, quando de acordo com a norma, ela devia está a 1,10m de altura.

Figura 3 - Portas e rampas de acesso à escola.

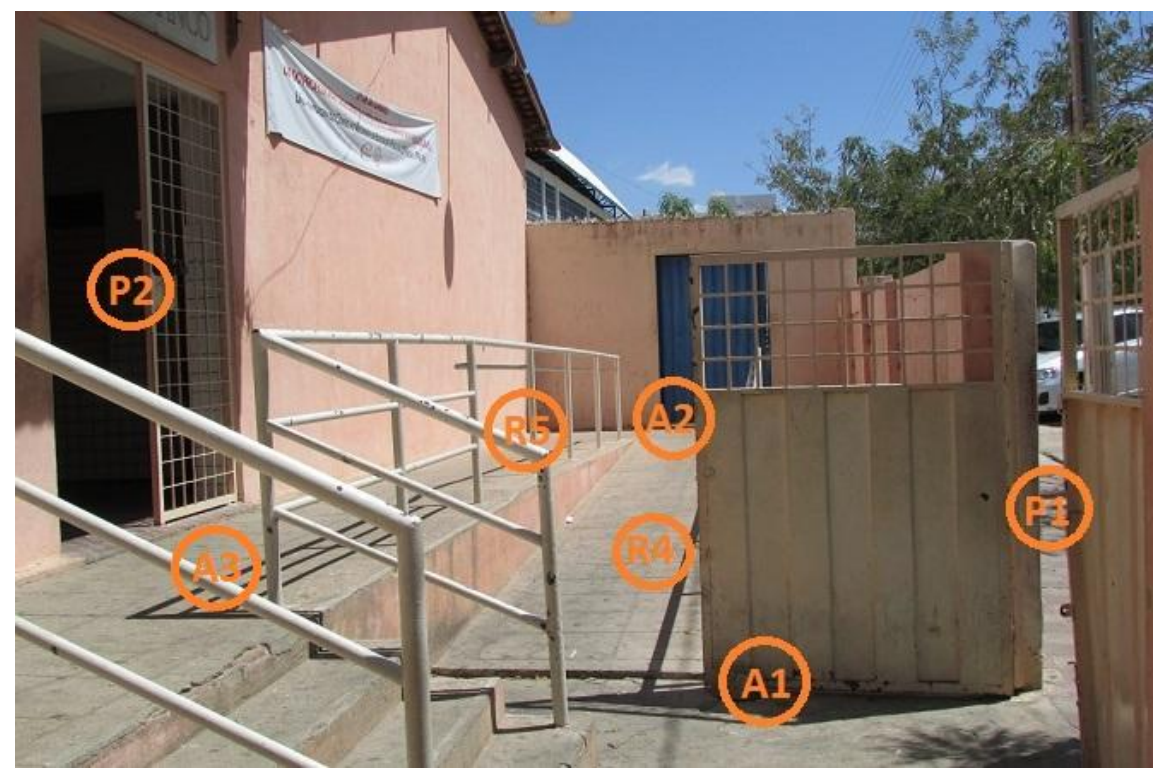

Fonte: Acervo pessoal.

A fechadura da figura 4 está presente na grande maioria das portas da Escola Rio Branco. Pela foto pode ser percebido o nível de deterioração da mesma, com ferrugem que a faz emperrar, além de ter uma placa de metal que dificulta o acesso à mesma por um dos lados. 


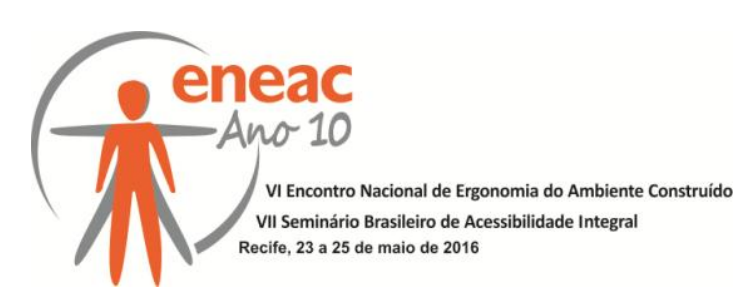

Figura 4 - Fechadura (ferrolho).

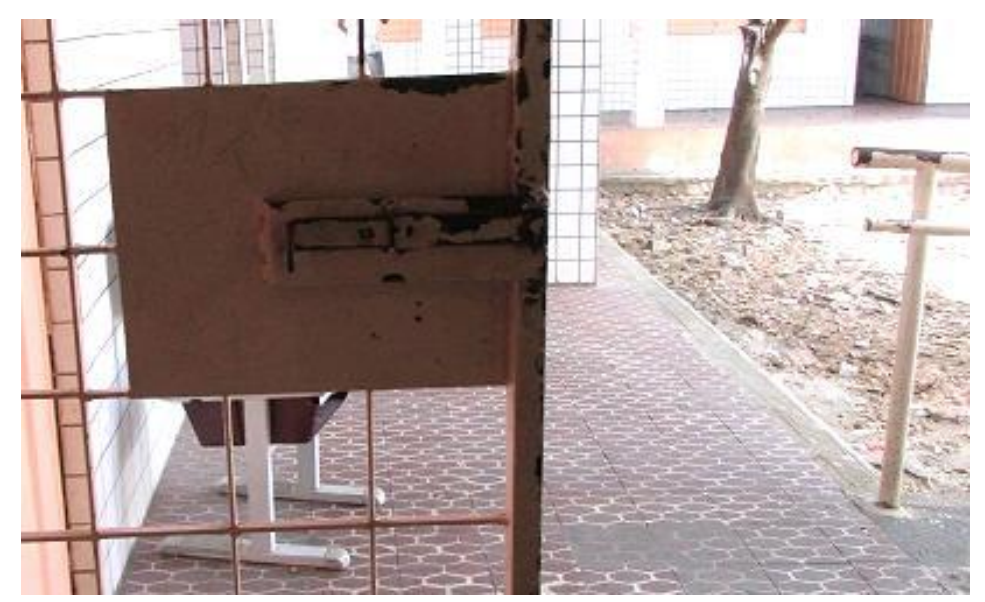

Fonte: Acervo pessoal.

A porta P3 tem largura de $0,95 \mathrm{~m}$, insuficiente para o grande fluxo de pessoas que a usam. Sua altura é de $2,25 \mathrm{~m}$. A fechadura está a uma altura de $1,13 \mathrm{~m}$ do piso, quando a norma exige a altura entre $0,90 \mathrm{~m}$ e $1,10 \mathrm{~m}$, portanto está inadequada. Ela é semelhante à fechadura da figura 5 e possui os problemas já mencionados.

A área para manobra de $90^{\circ}$ A4 possui dimensões de $1,35 \mathrm{~m}$ de largura e de comprimento, estando adequada, porém os corredores $\mathrm{C} 1$ e $\mathrm{C} 2$ tem largura livre de $1,35 \mathrm{~m}$, quando deveriam ter largura de pelo menos $1,50 \mathrm{~m}$, como a norma orienta para corredores internos de uso público. Além disso, esse corredor, assim como os outros que serão analisados a seguir, possui desnível em um dos lados e nenhum guarda-corpo ou sinalização tátil para auxiliar a segurança dos usuários.

Figura 5 - Porta P3 e áreas de circulação

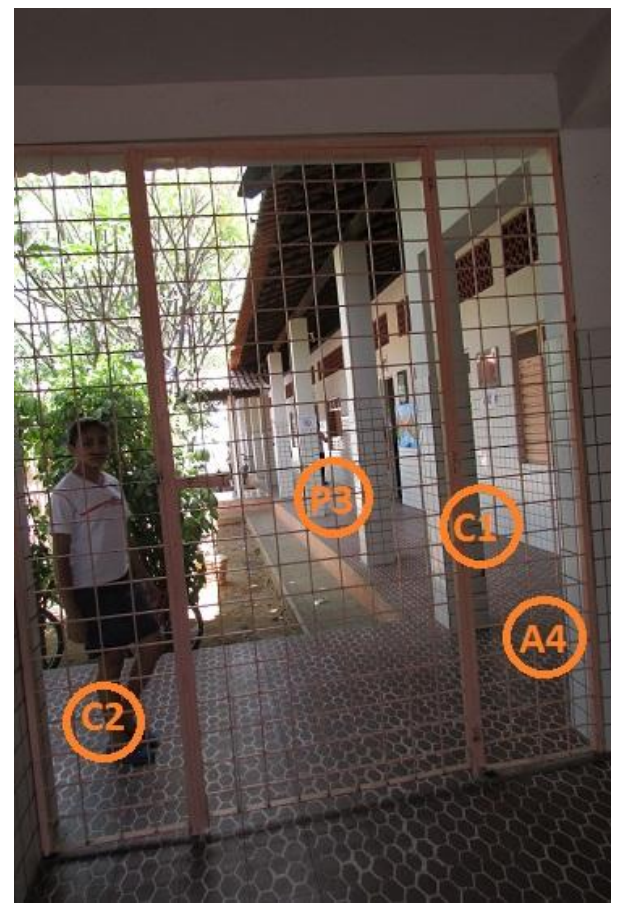

Fonte: Acervo pessoal. 


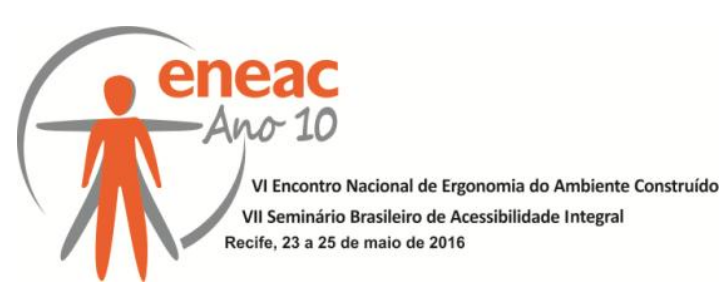

O corredor C3 possui largura de 1,80m, acima dos 1,50m que a NBR normatiza. A área para manobra de $90^{\circ}$ formada pelos corredores C1 e C3 é suficiente de acordo com a norma.

Já a rampa R6 tem largura de 0,60m quando de acordo com a NBR 9050 (ABNT, 2015) a largura mínima deve ser de $1,20 \mathrm{~m}$. A altura de $0,34 \mathrm{~m}$ e o comprimento de $1,10 \mathrm{~m}$ dessa rampa corresponde a uma inclinação de $31 \%$, em desacordo com a norma. Assim, essa rampa precisaria ter comprimento de $4,08 \mathrm{~m}$ para ficar com inclinação de $8,33 \%$, que é o mínimo admitido pela norma. Portanto, é impraticável o acesso de uma pessoa com deficiência à biblioteca. Não há nenhum tipo de corrimão, sinalização tátil ou visual, o que apresenta um grande risco para os usuários da instituição, já que o piso é escorregadio e elevado, podendo ocasionar quedas.

\section{Figura 6 - Áreas de circulação e rampa R6 de acesso à biblioteca P4.}

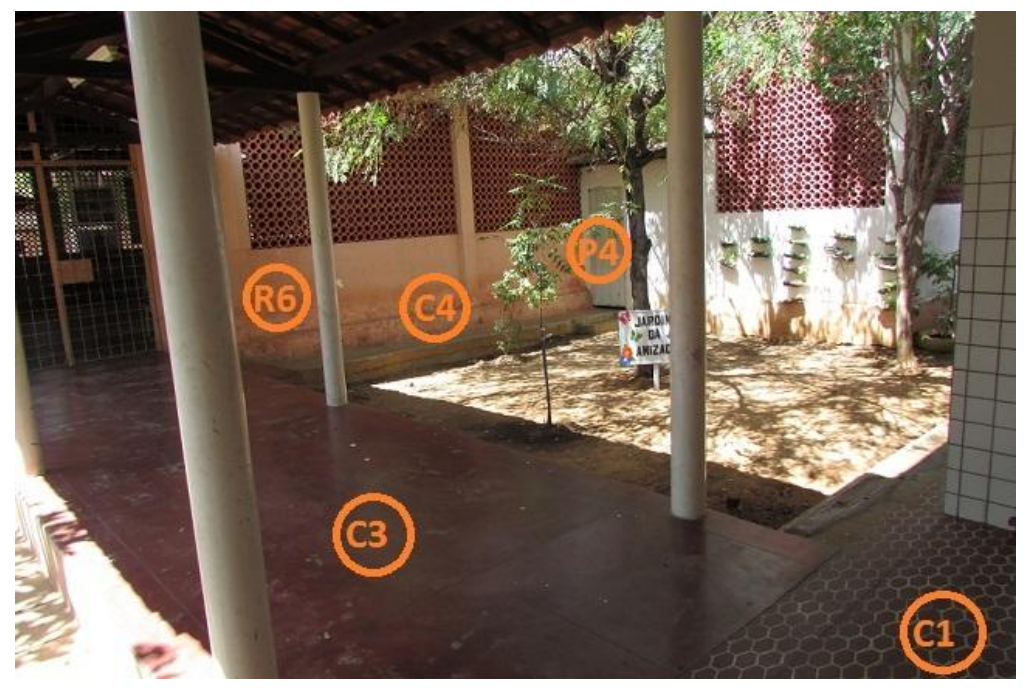

Fonte: Acervo pessoal.

O corredor C4 que dá acesso à biblioteca tem apenas $0,60 \mathrm{~m}$ de largura, portanto está inadequado e torna a biblioteca inacessível.

A porta P4 (Figura 7) possui apenas $0,77 \mathrm{~m}$ de largura quando o mínimo tolerado pela norma é uma largura de $0,80 \mathrm{~m}$, além de um desnível de $3 \mathrm{~cm}$ na entrada, que torna ainda mais difícil o acesso à sala. A altura é de $2,10 \mathrm{~m}$, portanto condiz com o que a norma pede. As fechaduras são totalmente inadequadas, estando a mais baixa a uma altura de $0,63 \mathrm{~m}$ e a mais alta a uma altura de $1,50 \mathrm{~m}$ do piso, quando devia haver apenas uma maçaneta de alavanca com altura entre 0,90m e 1,10m, como a NBR 9050 (ABNT, 2015) orienta. A porta não apresenta nenhum tipo puxador e sinalização. 


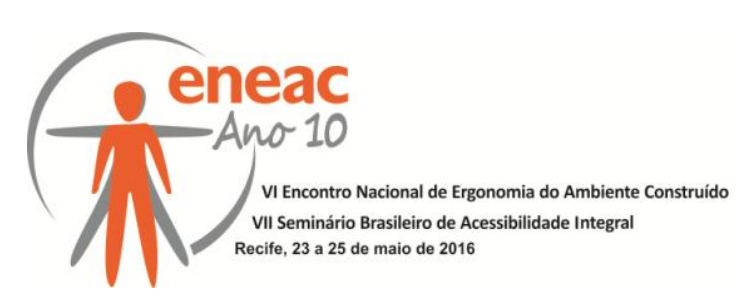

\section{Figura 7 - Corredor C4 e porta da biblioteca P4}

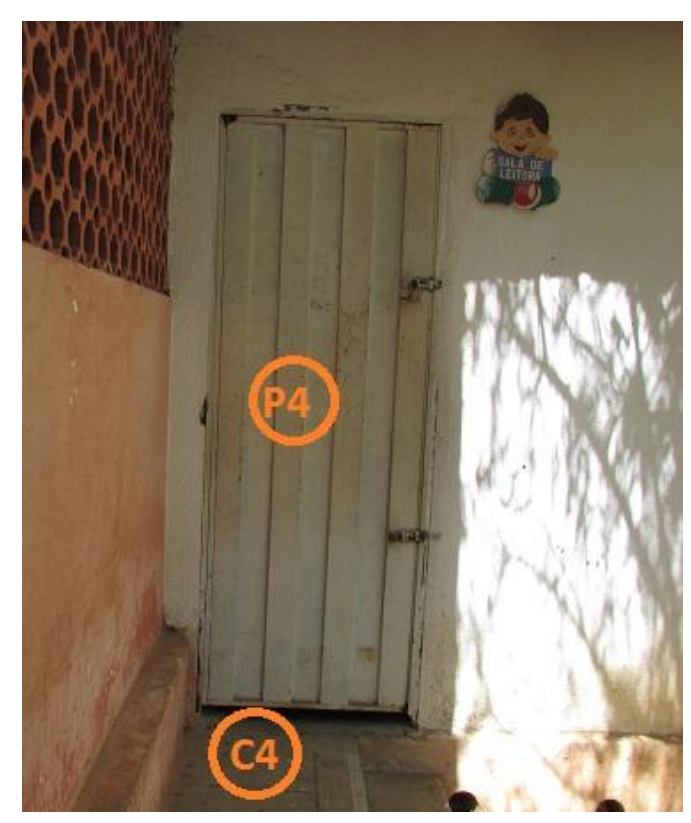

Fonte: Acervo pessoal.

A porta P5 tem altura de 2,25m e largura total de $1,12 \mathrm{~m}$, estando adequada. A fechadura é igual à vista na figura 5, estando em desacordo com o que estabelece a NBR 9050 (ABNT, 2015).

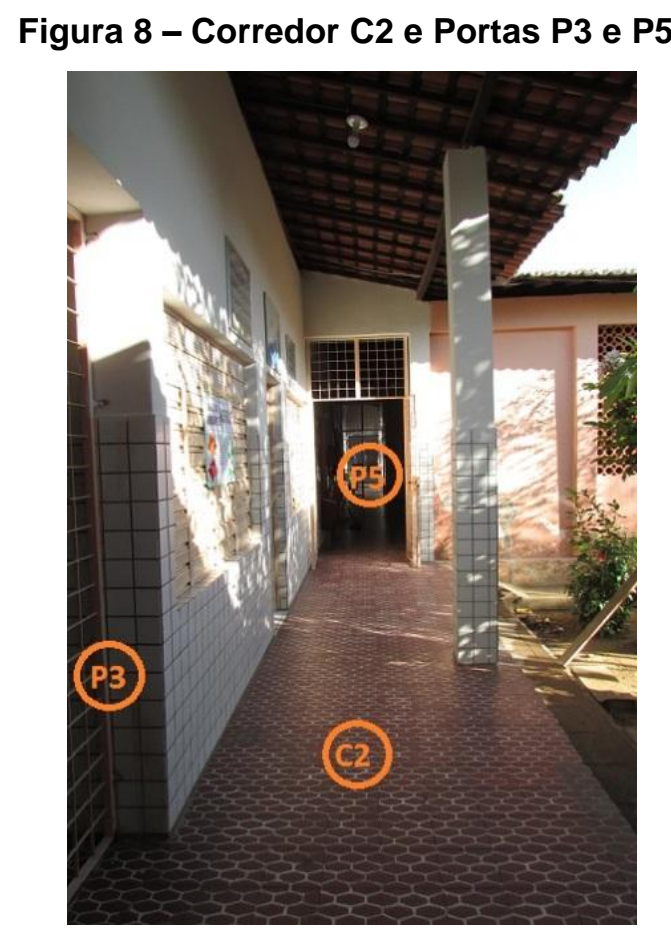

Fonte: Acervo pessoal.

A porta $\mathrm{P} 6$ possui dimensões iguais às da porta $\mathrm{P} 5$, portanto tem análise equivalente. $\mathrm{O}$ corredor C5 também equivale aos corredores C1 e C2, apresentando os mesmos problemas já elencados. 


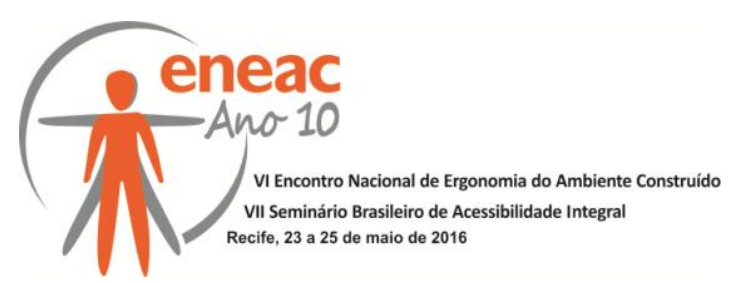

A área para manobra de $90^{\circ}$ A5 que fica na entrada para o banheiro, tem dimensões que possibilitam a realização da manobra pelo cadeirante, porém há o problema do grande fluxo no corredor estreito, que pode atrapalhar a entrada ao banheiro.

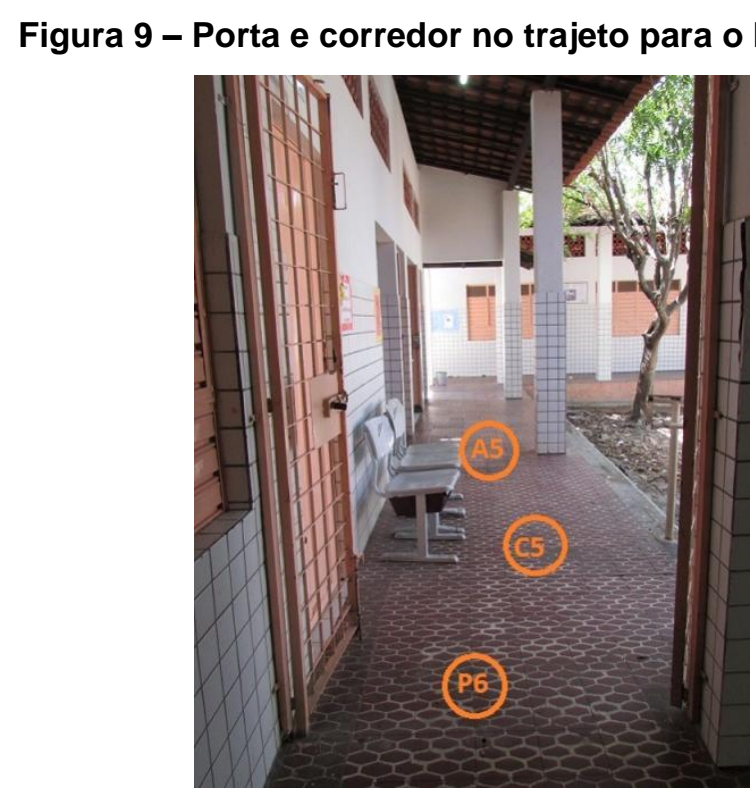

Fonte: Acervo pessoal.

No corredor C5 há cadeiras dispostas para funcionários. As cadeiras são removíveis, mas geralmente se encontram neste local, tornando-se barreiras. O corredor possui $1,50 \mathrm{~m}$ de largura, uma pessoa sentada em uma cadeira ocupa $0,70 \mathrm{~m}$, restando apenas um total de $0,80 \mathrm{~m}$ de largura. A largura para a passagem da cadeira de rodas esta adequada, porém uma circulação de uso público deveria ter no mínimo 1,50m de largura de acordo com a NBR 9050(ABNT, 2015).

Figura 10 - Corredor C5 com barreiras

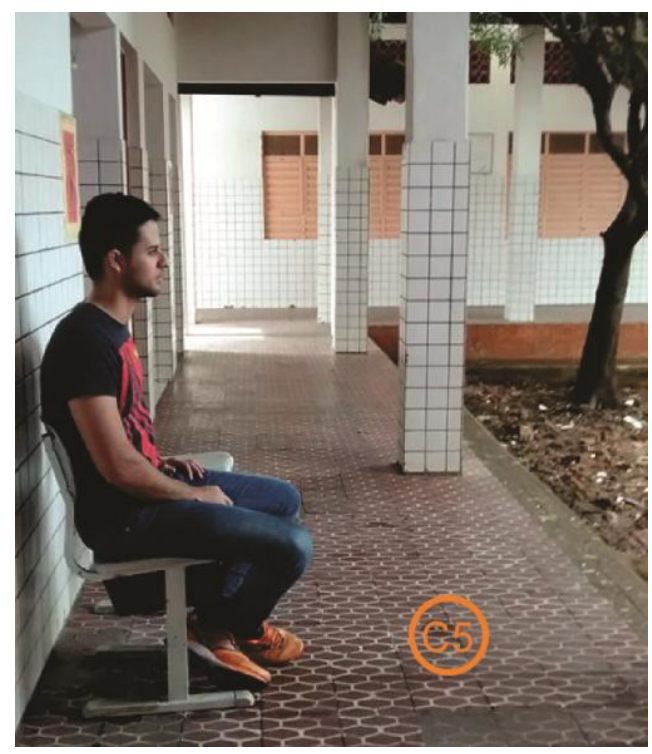

Fonte: Acervo pessoal. 


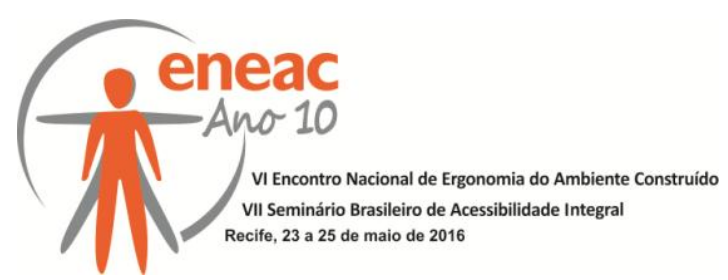

A porta do banheiro acessível P7 possui 2,10m de altura e $0,90 \mathrm{~m}$ de largura, estando adequada de acordo com a NBR 9050 (ABNT, 2015). A norma especifica que a sinalização para portas de banheiros deve ter contornos fortes, com imagens simples e bem definidas de acordo com padrões internacionais para facilitar a identificação por pessoas com baixa visão ou idosas, por exemplo. Porém, na porta deste banheiro não há nenhum tipo de sinalização indicativa.

Essa porta deveria ter revestimento contra impacto até $0,40 \mathrm{~m}$ de altura, para evitar sua deterioração devido a choques de muletas, andadores, cadeiras de rodas, etc. A porta também necessita de um puxador horizontal a $0,90 \mathrm{~cm}$ do piso, conforme orientação na norma. A maçaneta de alavanca é a única que está adequada em todo o trajeto analisado.

O banheiro não possui lavatório em seu interior, tendo apenas um lavatório externo. Este espaço é utilizado como área de serviço e lavanderia da escola.

Figura 11- Porta P7 do banheiro para deficientes.

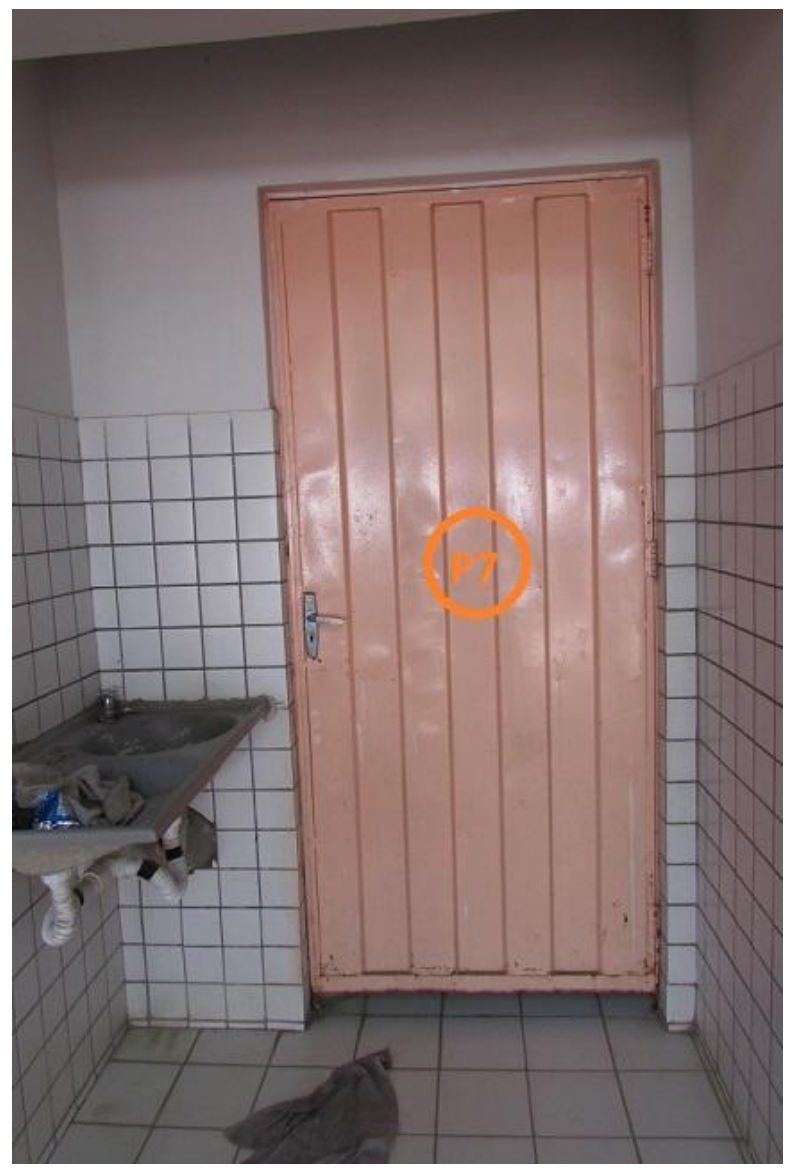

Fonte: Acervo pessoal.

O banheiro tem $1,50 \mathrm{~m}$ de largura e $1,80 \mathrm{~m}$ de comprimento, resultando em uma área de $2,70 \mathrm{~m}^{2}$, o que seria suficiente para a manobra de $180^{\circ}$, de acordo com a NBR 9050 (ABNT, 2015), porém há uma máquina de lavar instalada dentro do mesmo sobre um patamar de $0,70 \mathrm{~m}$ de largura por $0,67 \mathrm{~m}$ de comprimento, totalizando uma área de $0,47 \mathrm{~m}^{2}$, que ocupa $17 \%$ da área do banheiro, tornando-o inadequado para uso de uma pessoa com deficiência, principalmente um cadeirante. 


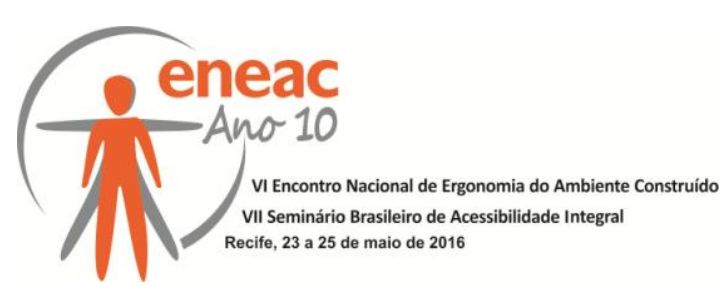

A bacia sanitária possui altura de $0,40 \mathrm{~m}$ sem o assento, quando a norma considera admissível uma altura entre $0,43 \mathrm{~m}$ e $0,45 \mathrm{~m}$. Além disso, as barras de apoio estão incorretas. Deveria haver três barras: uma horizontal paralela ao vaso sanitário, uma horizontal perpendicular ao vaso e uma vertical acima da horizontal paralela. As barras horizontais devem ter $0,75 \mathrm{~m}$ de altura, de acordo com a norma, porém estão a 0,80m de altura.

Além dos erros já identificados, deve-se salientar que esse é o único banheiro acessível da escola, que se encontra inadequado para uso de pessoas com deficiência. Esse banheiro tem dimensões destinadas ao uso de adultos, como altura do vaso e altura das barras, no entanto a escola atende principalmente crianças e adolescentes. Logo, deveria haver no mínimo dois banheiros acessíveis, um adulto e um infantil.

Figura 12 - Banheiro para deficientes.

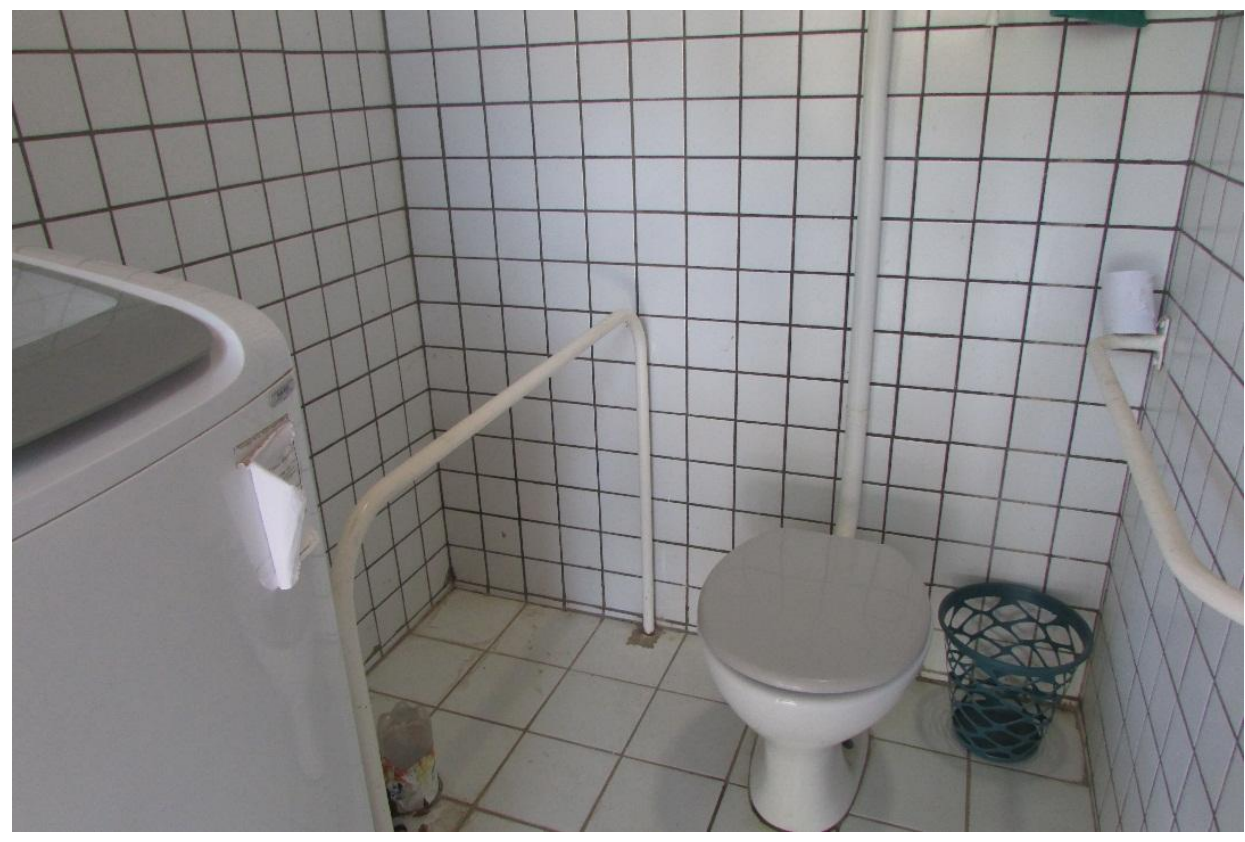

Fonte: Acervo pessoal.

\section{CONCLUSÕES}

A falta de preocupação na adequação da Escola Rio Branco à NBR 9050 (ABNT, 2015) representa desrespeito e falta de segurança aos usuários desta instituição de ensino. A ausência de sinalização, guarda-corpos, piso tátil, piso antiderrapante, além dos corredores estreitos, dificulta a circulação de pessoas com deficiência ou mobilidade reduzida, influenciando diretamente na autonomia desses.

Até mesmo pessoas com deficiência auxiliadas não teriam acesso à biblioteca ou ao banheiro, que teve sua área comprometida pela inserção de uma máquina de lavar. Além do transtorno para um possível visitante desta escola, a inadequação da mesma à norma de acessibilidade, torna impraticável o ingresso de um aluno ou profissional com deficiência à instituição, indo contra os direitos dos cidadãos, a política de inclusão e erradicação da discriminação.

Tudo isso representa um descaso do poder público e falta de fiscalização dos órgãos responsáveis por proteger os direitos da população, como o Ministério Público. 


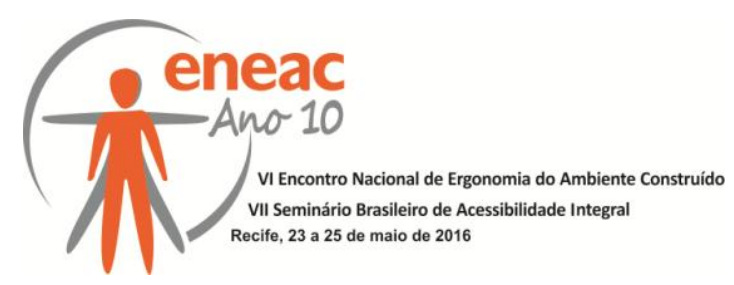

\section{REFERÊNCIAS BIBLIOGRÁFICAS}

Associação Brasileira de Normas Técnicas. NBR 9050: Acessibilidade a edificações, mobiliário, espaço e equipamentos urbanos. 3. Ed. Rio de Janeiro, 2015. 148p.

BRASIL. Decreto no 5.296 de 2 de dezembro de 2004. Regulamenta as Leis nos 10.048, de 8 de novembro de 2000, e 10.098, de 19 de dezembro de 2000.

BRASIL. Lei no 13.146, de 06 de julho de 2015. Institui A Lei Brasileira de Inclusão da Pessoa Com Deficiência: Estatuto da Pessoa com Deficiência.

IBGE. CENSO Demográfico 2010. Disponível em: <http://www.ibge.gov.br>. Acesso em: 29/11/2015.

MORAES, Anamaria. MONT'ALVÃO,Claúdia. Ergonomia: Conceitos e Aplicações. $4^{\mathrm{a}}$ edição. Rio de Janeiro:2AB, 2009. 224p.

DISCHINGER, M.; MACHADO, R. . Desenvolvendo ações para criar espaços escolares acessíveis. Inclusão (Brasília), Brasilia, v. 02, n.ago2006, p. 33-39, 2006. 